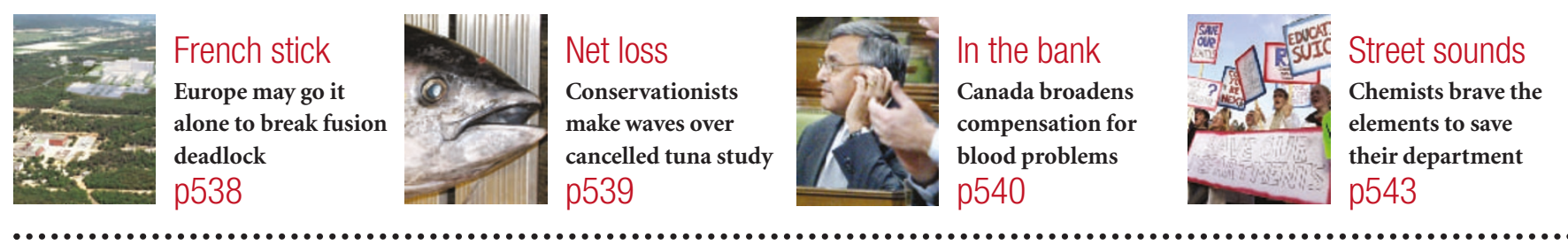

\title{
Suppressed study raises spectre of flawed drug regulation in US
}

Emma Marris, Washington

Amid claims that it suppressed publication of a study into the safety of a painkiller, the US Food and Drug Administration (FDA) is under increasing pressure to reform the way in which it monitors approved drugs.

Vioxx, a prescription painkiller made by New Jersey-based Merck, was withdrawn by the company on 30 September after a study it had commissioned linked the drug to an increased risk of heart attacks.

But the FDA - the world's largest drug regulator - is facing detailed allegations that it pressed one of its top drug-safety officials to withdraw a paper on Vioxx from publication in The Lancet. The study, led by David Graham, associate director for science at the FDA's Office of Drug Safety, also linked the drug to heart attacks. Graham estimates that Vioxx has been responsible for several thousand deaths since it was approved in 1999.

On 18 November, Graham, a 20-year FDA veteran, vaulted into the national spotlight when he testified at a Senate hearing on Vioxx that the agency was "broken". The hearing raised questions about why the FDA waited for Merck to take action, when Graham's preliminary data earlier in the year had suggested that the drug should be withdrawn.

Now the agency is under attack for suppressing Graham's Vioxx paper, which he hoped to publish at the time of the hearing. According to extracts from e-mails printed in USA Today on 29 November, Steven Galson, acting director of the FDA's Center for Drug Evaluation and Research, contacted editors at The Lancet and made reference to an internal FDA report that contained allegations that Graham might have manipulated data in his study.

Richard Horton, The Lancet's editor, reacted with irritation. "One could read such an allegation as an attempt to introduce doubt into our minds about the honesty of the authors," he wrote, "doubt that might be sufficient to delay or stop publication of research that was clearly of serious public interest."

The FDA said in a statement that Graham had submitted the paper "without going through the long-established peer review and clearance process established for scien-

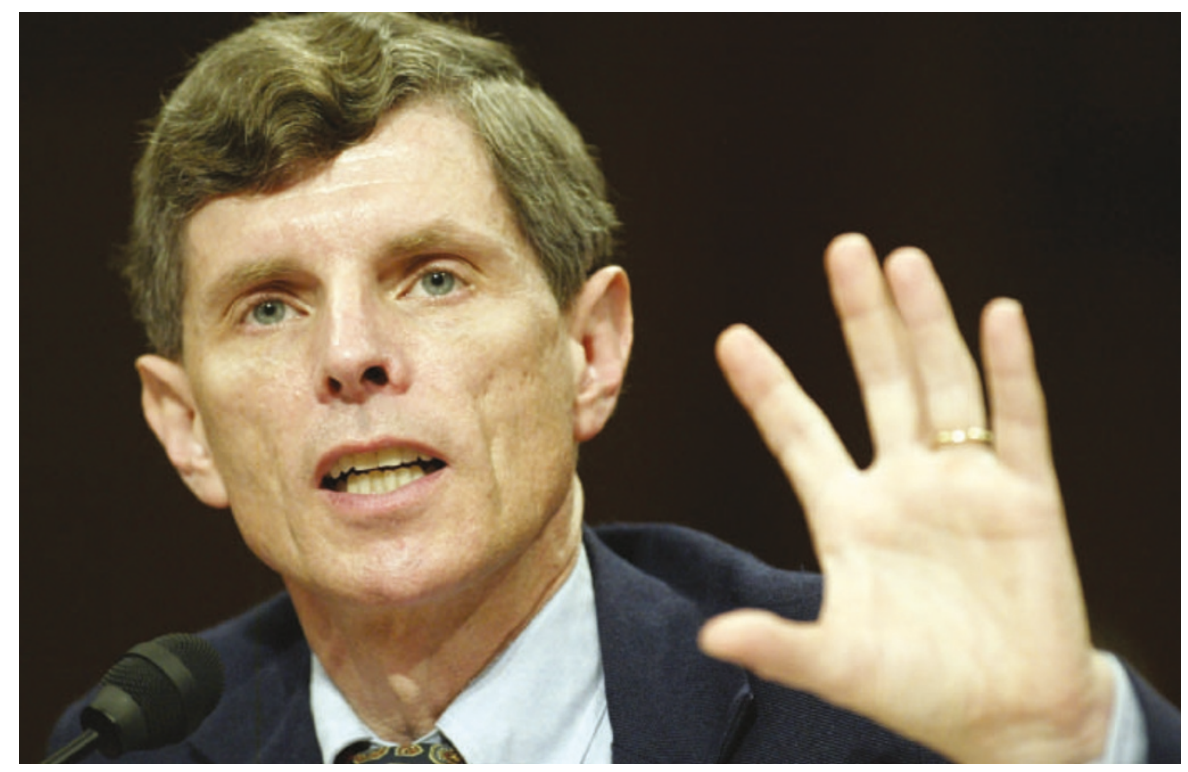

Safety check: David Graham testifies at a Senate hearing, claiming that the FDA is 'broken'.

tific papers submitted by FDA scientists".

Graham says that the charges of data manipulation arose from corrections that he made between an earlier abstract and the final version of the paper. He ultimately withdrew the paper on 16 November, saying that he feared for his job. "I got a very explicit e-mail from Dr Galson saying I could not let it be published, and if I did, I and The Lancetwould be responsible for the consequences." He says he may now remove his name from the study so that it can be published without the need for FDA approval. "The FDA is engaged in an act of scientific censorship," he claims.

\section{Under pressure}

Graham says he is now being pressured by Lester Crawford, the FDA's acting commissioner, to accept a transfer to a desk job, and expects to be ordered to move within the week. "I am a scientist," he says. "Removing me would be an act of retaliation."

In a statement, the FDA said that it does not "condone any form of employee retaliation. In fact, as we have repeatedly stated, we encourage internal scientific debate."

Alastair Wood, an associate dean of Vanderbilt University in Nashville, Tennessee, and one-time contender for the post of FDA commissioner, slammed the agency's response to the Vioxx affair, which he says probably killed more people than the 11 September terrorist attacks. "We've had a major public-health disaster," he says. "Yet we have no forum for open discussion, no way to move forward. Instead, each side has got into their bunkers."

And Vera Sharav, president of the Alliance for Human Research Protection, a New Yorkbased patient-advocacy group, thinks the whole agency badly needs shaking up. "The leadership has to go," she says. "A firewall has to go up between FDA reviewers and industry."

But criticism of the drug-safety agency is reaching far beyond vocal groups such as Sharav's. The Journal of the American Medical Association has just published an editorial calling for the Office of Drug Safety to be "decoupled" from the rest of the FDA (P. B. Fontanarosa et al. J. Am. Med. Assoc. 292, 2647-2650; 2004). And Senator Chuck Grassley (Republican, Iowa), chair of the Senate finance committee, says that he will introduce legislation to move it from "under the thumb" of the Office of New Drugs, the powerful branch of the FDA responsible for drug approval. 